\title{
A cross-sectional study on the effects of occupational noise exposure on hypertension or cardiovascular among workers from automobile manufacturing company of Chongqing, China
}

\author{
Shuai Wang, Qizhong Qin, Lu Liu, Lingli Han, Yu Chen* \\ Department of Labor and Environmental Health, School of Public Health and Management, Chongqing Medical University, \\ Chongqing, China \\ Email: $\underline{\text { chenyu@,cqmu.edu.cn }}$
}

Received 14 October 2013; revised 16 November 2013; accepted 28 November 2013

Copyright (C) 2013 Shuai Wang et al. This is an open access article distributed under the Creative Commons Attribution License, which permits unrestricted use, distribution, and reproduction in any medium, provided the original work is properly cited. In accordance of the Creative Commons Attribution License all Copyrights (C) 2013 are reserved for SCIRP and the owner of the intellectual property Shuai Wang et al. All Copyright (C) 2013 are guarded by law and by SCIRP as a guardian.

\begin{abstract}
For the past few years, noise pollution has been more and more serious, and it may lead to several diseases. While the humans expose to noise in quantity for a long time, their blood pressure will change, and even cause changes in cardiac function. In our study, we attempt to find the relationship between occupational noise and hypertension and impaired hearing, cardiac function. It may be helpful to obtain some useful information on occupational noise exposure of humans. The participants were divided into noisy group $\geq 90$ dB (A) and non-noisy group $\leq 70 \mathrm{~dB}$ (A). We performed this research in an automobile manufacturing company of Chongqing, China during 2011-2012. Our study showed that there may be positive associations between occupational noise and hypertension and impaired hearing, but no conclusion can be drawn between occupational noise and ECG.
\end{abstract}

Keywords: Occupational Noise; Hypertension; Impaired Hearing; Automobile Manufacturing Company; Health Examination

\section{INTRODUCTION}

Noise, defined as the boring or unnecessary sound, exists in the environment and workplaces widely. Nowadays, noise pollution has been an important problem which is prevalent in the world [1-4]. Simultaneously, occupational noise is also the main section and a large number of workers are suffering a high level of noise un-

\footnotetext{
"Corresponding author.
}

acceptable. Chongqing City is an important large-scale industrial city in China, including shipping, metallurgy, automobile manufacturing, war industry and so on, and automobile manufacturing industry is one of the pillar estates (close to 250 thousand workers) $[5,6]$. Most of the workers have to exposure high level of noise while working in workshops, so what effects of the occupational noise would exert on workers is one of the most important issues. However, there has been little research about occupational noise and workers' health in China.

Noise exposure can induce hearing impairment or even hearing loss, but whether the workers working under noisy environment are inclined to influence the blood pressure or cardiovascular function is controversial. Some research supports the relations between noise exposure and hypertension or cardiovascular changes [7-11]. In contrast, some investigators consider that there are no associations between noise exposure and hypertension or cardiovascular reactions [12-14]. Dutch researchers found that different races showed different relationships between noise and blood pressure [15]. From this study we know different races may show various reactions under noise exposure, hence, studies in different people are necessary.

To estimate whether or not workers working under noisy environment will influence the blood pressure or cardiovascular parameters in Chongqing, we perform a health examination on automobile workers $(\mathrm{n}=728)$.

\section{MATERIALS AND METHODS}

\subsection{Participants}

1050 workers of an automobile factory received occupa- 
tional health examinations held by the Center for Disease Prevention and Control of Chongqing from November, 2011 to March, 2012. This study performed with the Recommendations from the Declaration of Helsinki (1983) and was approved by every subject and the ethics committee of Chongqing Medical University, Chongqing, before conducting it. Eliminating 35 workers who had cardiovascular diseases before working in this company and 287 workers who worked under the noise exposure $(75.0-88.2 \mathrm{~dB}$, mean $=78.6 \mathrm{~dB})$. Checking all the items, the results of 728 workers were collected and analyzed in the study. The workers who received health examination were obtaining written informed consent (men 588, women 140) and then taking medical examinations, including general medical check, audition screening, blood pressure, electrocardiogram, blood test, X-ray, ophthalmology and otorhinolaryngology, type-B ultrasonic, liver function, lung function routine examinations etc. All the examinations were carried out between 9:00 and 12:00, requesting all workers to take test and not to eat anything until completing the examinations day ahead.

Questionnaires with all inspection items were distributed to every worker the day before checking up and objects were requested to paste the copy of identification card on the top left corner of the cover and to fill in essential information (including name, sex, age, weight, body height and so on), history of diseases, smoking years, drinking years, diet habits and so on. Whether the family had hypertension or other cardiovascular diseases was included in the history of diseases.

For the present study, the workers $(n=728)$ were assigned into noisy group and non-noisy group, different types of work in production had different levels of noise, so 442 workers from workshops where the level of noise was $\geq 90 \mathrm{~dB}$ (A) were divided into noisy group, and another 286 workers from office rooms and one depository where the level of noise was $\leq 70 \mathrm{~dB}$ (A) were divided into non-noisy group, none of the workers used ear protectors.

\subsection{Determination of Workplace Noise}

The levels of noise exposure were measured by sound level meters (TES-1357 sound level meter, Taiwan), workshops, offices and two depositories were all measured from 9:00 to 17:00 consecutively. The meters were placed $1.5 \mathrm{~m}$ above the workshops' ground surface and $1.1 \mathrm{~m}$ above the offices' and depositories' ground surface. To exclude the interference of results by wind, we surveyed the wind velocity of all destinations which were all below $1 \mathrm{~m} / \mathrm{s}$. The average A-weighted sound levels of $8 \mathrm{~h}$ were accounted before examinations, those who worked in the environment which the average level and the maximum level both $\leq 70 \mathrm{~dB}$ (A) were assigned into non-noisy group. Similarly, the average level and the minimum level both $\geq 90 \mathrm{~dB}$ (A) were assigned into noisy group. The level of noise in one depository was $80.2 \mathrm{~dB}$ and workplaces which some cleansers worked were between $75.0-88.2 \mathrm{~dB}$ (mean $=78.6$ ), so these workers were excluded from the research.

\subsection{Determination of Blood Pressure}

The measurements of blood pressure were performed in a quiet room in the morning using mercurial sphygmomanometer, conducted by the policy of Bailey and Bauer [16]. The workers must have a rest at least for $10 \mathrm{~min}-$ utes before entering the room, and then were guided in the sitting position after about 5 minutes rest testing the blood pressure of brachial artery for three times, the data was used in mean of them to express individuals' blood pressure in this study. Hypertension was defined by the World Health Organization: a systolic BP $\geq 140 \mathrm{mmHg}$ or a diastolic BP $\geq 90 \mathrm{mmHg}$, or had been treated for hypertension [17].

\subsection{Determination of ECG and Hearing}

In this study, doctors used electrocardiographs (ECGE31A, Guangdong, SHENZHEN ORIENTAL SCIENCE \& TECH. CO. LTD) to test every participant's ECG, and they determined weather normal or abnormal by the results of examinations. In these workers, the types of abnormal were sinus tachycardia, sinus bradycardia, left axis deviation, right axis deviation, premature ventricular contraction, sinus arrhythmia, incomplete right bundle branch block and hart rate over 100 times/min; when a worker had one of these symptoms was defined as abnormal ECG. After taking examinations, we collected all the data together to analyze.

Simultaneously, doctors use audiometers (MM622, Denmark, Madsen) to test every participant's hearing, and they determined weather normal or abnormal by the results of audiogram. The abnormal hearing ability of most workers of was $\mathrm{V}$ type audiogram, when the average value of $3000 \mathrm{~Hz}-6000 \mathrm{~Hz}>50 \mathrm{~dB}$ was defined as hearing impairment.

\subsection{Statistical Analyses}

In this study, we used the logistic regression to analysis the relations between noise and hypertension, ECG, impaired hearing, and used $x^{2}$ test to compared the differences between noisy group and non-noisy group, including the rate of hypertension, the abnormal rate of ECG, the abnormal rate of hearing and the rate of them in different working years. All the values are presented as means \pm SD, and analyzed by SPSS17.0 $(\mathrm{a}=0.05)$.

\section{RESULTS}

In present study, all questionnaires were collected by 
staffs of the CDC after health examination, and then all data was recorded as Excel format in computers. BMI was calculated and showed a decrease in noisy group but did not reach statistical significance (data not shown).

As shown in Table 1, more than one fifth workers were diagnosed with hypertension $(21.49 \%)$ in noisy group and was significance compared with non-noisy group ( $<<0.01)$. Equally, workers who worked in noisy worksites had a worse audition than those who worked in control conditions $(\mathrm{p}<0.01)$, while ECG presented an increase abnormal rate but showed no significance.

In this factory, about one fifth workers are women and four fifth workers are men, to eliminate the effects of sexuality we compared sex structure between two groups which shown no significant difference (data not shown). Both in two groups, the rate of hypertension in women was significantly higher compared with men; in noisy group was higher than non-noisy group $(\mathrm{p}<0.01)$. On the contrary, the prevalence of ECG in women was lower compared with men but still showed no significant difference $(p>0.05)$. The percentage of hearing damage was similar in men and women, no significance was observed in Table 2.

The rates of hypertension and audiometric injuries were significantly increased $(p<0.01)$ with working years growing in noisy group, but this trend was not seen in ECG. Only in noisy group, ECG among workers worked 10-year were significantly higher than those who worked 0 -year, workers who worked more than 15 years increased but did not reach statistical significance. In non-noisy group, ECG was no significant difference among working years groups. As is shown in Table 3, the rate of impaired hearing indicated an increase with working years while 15- group was below significance ( $p$ $>0.05$ ).

After analyzed the data shown in previous tables, we further used the logistic regression statistics and the results are presented in Table 4. The total odds ratios of hypertension, ECG, impaired hearing were 2.63, 1.19, 2.21 and the $95 \%$ CI were $1.66-4.15,0.76-1.86,1.31$ 3.70. To certify the relation of noise and hypertension, ECG, impaired hearing, we must evacuate the effects of other factors such as age, BMI, lifestyle items (including smoking, drinking, exercise, diet and so on). The results after adjusted these factors were shown in Table 4.

\section{DISCUSSION}

Nowadays, noise pollution has been an important problem in the world. Many studies researched about occupational noise exposure and hearing, blood pressure, cardiovascular changes in various countries [18-23], however, similar research was seldom carried out in China and no report was found in large-scale industrial city of Chongqing. To resolve this problem in the area, we did this study. In the study, we found the percentage of hypertension in the noise exposure group was significantly higher than the control group. This result was in accordance with previous studies [9,24-27]. These studies reported that there was a positive relation between hypertension and noise exposure, and some of them analyzed the possible reasons. 1301 workers in Taiwan were used independently and joint effect methods suggested that those who have TT variant allele (one genotype of angiotensinogen gene) would get hypertension easily [25]. In addition, there were different effects when the metabolic syndrome (MetS) was defined differently while occupational exposure to workload or noise adjusted coronary heart disease (CHD) risk. When MetS defined by high triglycerides, BMI and low HDL-C, the occupational noise exposure has a protective effect and can decrease the risk of CHD. While if MetS defined by high blood pressure, BMI and glucose, no protective effect is shown [26], and when noise exposure above $80 \mathrm{~dB}$ (A) correlated with hypertension and $4000 \mathrm{HZ}$ has the most enormous effect [9]. All these are the possible reasons for why noise could impact blood pressure of people.

In our study, we found another special phenomenon that the prevalence of hypertension in women was significant higher than men, and the result was not consistent with the previous study [28]. The possible reasons were as follows: firstly, men both in noisy and non-noisy group did more physical work than women; secondly, fat accumulated with age and exorbitant fat of body was one of induced factors leading to hypertension, and body fat of women is higher than men with age increasing; thirdly, the questionnaires showed most of male workers had a drinking habit about $50-100 \mathrm{ml} /$ day, and only a few of them were used to drinking abuse.

ECG is the main parameter responding the functions of cardiovascular, weather noise exposure is related with it or not is controversial. The abnormal rate of it in our study presents that there may be no associations with occupational noise. The result is not in concordance with some previous studies which showed no relations between noise exposure and hypertension or cardiovascular diseases [29-31]. This may be as a result of the data only collected from a company, and in order to achieve a more credible conclusion, further research on general population is needed in our team.

The rate of hypertension and impaired hearing increased with noise exposure years, and we analyzed the data by the logistic regression model. The results showed positive relations between occupational noise exposure and hypertension, impaired hearing. The possible confounding factors are age, BMI, smoking, drinking, exercise, diet and so on. A study suggested that BMI, waist circumference and weight were associated with chronic diseases such as hypertension, hyperlipemia and diabetes 
Table 1. Detection rate of hypertension, ECG and impaired hearing in two exposure groups.

\begin{tabular}{ccccc}
\hline & All $(\mathrm{n})$ & Hypertension $\%(\mathrm{n})$ & ECG \% (n) & Impaired Hearing \% (n) \\
\hline Noisy group & 442 & $21.49(95)^{* *}$ & $13.80(61)$ & $14.25(63)^{* *}$ \\
Non-noisy group & 286 & $9.44(27)$ & $11.89(34)$ & $0.99(20)$ \\
p-value & - & 0.000 & 0.454 & 0.003 \\
All & 728 & $16.76(122)$ & $13.05(95)$ & $11.40(83)$ \\
\hline
\end{tabular}

Notes: The rates of hypertension, ECG and impaired hearing were used $x^{2}$ test to compared the differences between noisy group and non-noisy group. ECG: It was defined as the rate of workers who were diagnosed sinus tachycardia, sinus bradycardia, left axis deviation, right axis deviation, premature ventricular contraction, sinus arrhythmia, incomplete right bundle branch block or hart rate over 100 times/min. ${ }^{* *}$ p $<0.01$ noisy group vs non-noisy group.

Table 2. Detection rate of hypertension, ECG and impaired hearing in male and female groups.

\begin{tabular}{cccccccc}
\hline & \multirow{2}{*}{ All $(\mathrm{n})$} & \multicolumn{2}{c}{ Hypertension \% (n) } & \multicolumn{2}{c}{ ECG \% (n) } & \multicolumn{2}{c}{ Impaired Hearing \% (n) } \\
\cline { 3 - 7 } & & Noisy Group & Non-noisy Group & Noisy Group & Non-noisy Group & Noisy Group & Non-noisy Group \\
\hline Men & 588 & $10.54(62)^{\&}$ & $2.89(17)$ & $9.01(53)$ & $5.10(30)$ & $8.50(50)^{\&}$ & $2.55(15)$ \\
Women & 140 & $23.57(33)^{* * \& \&}$ & $7.14(10)^{*}$ & $5.71(8)$ & $2.86(4)$ & $2.21(13)$ & $3.57(5)$ \\
p-value & - & 0.000 & 0.017 & 0.205 & 0.258 & 0.767 & 0.707 \\
All \% (n) & 728 & $21.49(95)$ & $9.44(27)$ & $13.80(61)$ & $11.89(34)$ & $14.25(63)$ & $6.99(20)$ \\
\hline
\end{tabular}

Notes: To see the differences between men and women, the data used $x^{2}$ test to analyze. ${ }^{* * *} \mathrm{p}<0.05,0.01$ men group vs women group; ${ }^{\&},{ }^{\&} \mathrm{p}<0.05,0.01$ noisy group vs non-noisy group.

Table 3. Detection rate of hypertension, ECG and impaired hearing in different exposure years.

\begin{tabular}{cccccccccccccccc}
\hline $\begin{array}{c}\text { Working } \\
\text { years } \\
(\mathrm{y})\end{array}$ & $\begin{array}{c}\text { All } \\
(\mathrm{n})\end{array}$ & $\begin{array}{c}\text { Hypertension } \\
\%(\mathrm{n})\end{array}$ & p-value & $\begin{array}{c}\text { ECG } \\
\%(\mathrm{n})\end{array}$ & p-value & $\begin{array}{c}\text { Impaired } \\
\text { Hearing } \\
\%(\mathrm{n})\end{array}$ & p-value & $\begin{array}{c}\text { All } \\
(\mathrm{n})\end{array}$ & $\begin{array}{c}\text { Hypertension } \\
\%(\mathrm{n})\end{array}$ & p-value & $\begin{array}{c}\text { ECG } \\
\%(\mathrm{n})\end{array}$ & $\begin{array}{c}\text { p-value } \\
\text { Impaired } \\
\%(\mathrm{n})\end{array}$ & $\begin{array}{c}\text { Hearing } \\
\text { p-value }\end{array}$ \\
\hline $0-$ & 186 & $5.91(11)$ & - & $11.29(21)$ & - & $5.91(11)$ & - & 89 & $8.99(8)$ & - & $11.24(10)$ & - & $3.37(3)$ & - \\
$5-$ & 83 & $6.02(5)$ & 1.000 & $8.43(7)$ & 0.479 & $6.02(5)$ & 1.000 & 64 & $7.81(5)$ & 0.797 & $10.94(7)$ & 0.954 & $1.56(1)$ & 0.640 \\
$10-$ & 48 & $43.75(21)^{* *}$ & 0.000 & $22.92(11)^{*}$ & 0.037 & $27.08(13)^{* *}$ & 0.000 & 47 & $2.13(1)$ & 0.243 & $12.77(6)$ & 0.792 & $8.51(4)$ & 0.083 \\
$15-$ & 53 & $24.53(13)^{* *}$ & 0.000 & $18.87(10)$ & 0.147 & $13.21(7)$ & 0.139 & 53 & $16.98(9)$ & 0.156 & $13.21(7)$ & 0.726 & $11.32(6)$ & 0.127 \\
$20-$ & 72 & $62.50(45)^{* *}$ & 0.000 & $16.67(12)$ & 0.246 & $37.50(27)^{* *}$ & 0.000 & 33 & $12.12(4)$ & 0.862 & $12.12(4)$ & 1.000 & $18.18(6)^{*}$ & 0.002 \\
All & 442 & $21.49(95)$ & - & $13.80(61)$ & - & $14.25(63)$ & - & 286 & $9.44(27)$ & - & $11.89(34)$ & - & $6.99(20)$ & - \\
\hline
\end{tabular}

Notes: To assess the associations between the rate of hypertension, ECG or impaired hearing and noise exposure years, separately. ${ }^{* * *} \mathrm{p}<0.05,0.01 .5-, 10-$, 15 - and 20- groups vs 0 - group, respectively.

Table 4. Odds ratios of hypertension, ECG, impaired hearing in noisy and non-noisy group workers $(\mathrm{n}=728)$.

\begin{tabular}{|c|c|c|c|}
\hline & & Odds Ratio & $95 \% \mathrm{CI}$ \\
\hline \multirow[t]{4}{*}{ Hypertension } & & 2.63 & $1.66-4.15$ \\
\hline & adjusted by age & 3.64 & $2.01-6.60$ \\
\hline & adjusted by BMI & 3.89 & $2.08-7.28$ \\
\hline & adjusted by lifestyle factors & 3.56 & $1.98-6.39$ \\
\hline \multirow[t]{4}{*}{ ECG } & & 1.19 & $0.76-1.86$ \\
\hline & adjusted by age & 1.21 & $0.73-1.99$ \\
\hline & adjusted by BMI & 0.91 & $0.71-1.17$ \\
\hline & adjusted by lifestyle factors & 0.84 & $0.53-1.33$ \\
\hline \multirow[t]{4}{*}{ Impaired Hearing } & & 2.21 & $1.31-3.70$ \\
\hline & adjusted by age & 2.57 & $1.39-4.75$ \\
\hline & adjusted by BMI & 2.86 & $1.44-5.67$ \\
\hline & adjusted by lifestyle factors & 2.34 & $1.35-4.07$ \\
\hline
\end{tabular}

Notes: OR values were calculated and adjusted Confounding factors such as age, BMI, lifestyle items (including smoking, drinking, exercise, diet and so on). $\mathrm{OR}>1$ means positive correlations between hypertension, ECG or impaired hearing and noise exposure. 
mellitus [32]. To receive more credible results, we adjusted these factors. The values of OR were changing slightly, but the conclusions were invariable.

Finally, from this study we could draw several conclusions: 1) There may be a positive relationship between exposure occupational noise and hypertension and impaired hearing; 2) The risk of hypertension and impaired hearing increased with working years; 3) Whether occupational noise affected cardiovascular or not was unclear. Further study with more samples from different areas was needed; 4) Wearing personal protective equipments (PPE) is very important for workers, but the workers in the study hardly use them for various reasons. Therefore forcible measures should be taken to guarantee PPE wearing rate among workers in China.

\section{ACKNOWLEDGEMENTS}

We appreciate Professor Yu Chen, Dr. Mindi He, Yan Wang, Hongjuan $\mathrm{Wu}$ and Lu Liu for their hospitable and professional technical assistance. Grant support was from The Center for Disease Prevention and Control of Chongqing.

\section{REFERENCES}

[1] Clark, C., Crombie, R., Head, J., van Kamp, I., van Kempen, E. and Stansfeld, S.A. (2012) Does traffic-related air pollution explain associations of aircraft and road traffic noise exposure on children's health and cognition? A secondary analysis of the United Kingdom sample from the RANCH project. American Journal of Epidemiology, 176, 327-337. http://dx.doi.org/10.1093/aje/kws012

[2] Li, J.S. and Wang, J.H. (1981) Study on environmental noise pollution in Qingdao. Chinese Journal of Preventive Medicine, 15, 41-43.

[3] Ross, Z., Kheirbek, I., Clougherty, J.E., Ito, K., Matte, T., Markowitz, S., et al. (2011) Noise, air pollutants and traffic: Continuous measurement and correlation at a hightraffic location in New York City. Environmental Research, 111, 1054-1063. http://dx.doi.org/10.1016/j.envres.2011.09.004

[4] Malakootian, M. (2001) Noise pollution in Kerman-Iran. Iranian Journal of Public Health, 30, 31-36.

[5] Gao, Y., Zhong, X.N., Yang, Y.H. and Tian, K.C. (2012) Plasma lipid level and incidence of dyslipidemia in workers of Chongqing enterprises and institutions. Chinese Journal of Cardiovascular Diseases, 40, 432-435.

[6] Zhang, D.P., Li, J.F., Hu, C.L. and Huang, H. (2009) Prevalence and correlation factors of carotid atherosclerosis among the middle and old aged workers in an iron and steel corporation, Chongqing. Chinese Journal of Epidemiology, 30, 322-325.

[7] Aydin, Y. and Kaltenbach, M. (2007) Noise perception, heart rate and blood pressure in relation to aircraft noise in the vicinity of the Frankfurt airport. Clinical Research in Cardiology, 96, 347-358. http://dx.doi.org/10.1007/s00392-007-0507-y
[8] Bendokiene, I., Grazuleviciene, R. and Dedele, A. (2011) Risk of hypertension related to road traffic noise among reproductive-age women. Noise and Health, 13, 371-377. http://dx.doi.org/10.4103/1463-1741.90288

[9] Chang, T.Y., Liu, C.S., Young, L.H., Wang, V.S., Jian, S.E. and Bao, B.Y. (2012) Noise frequency components and the prevalence of hypertension in workers. Science of the Total Environment, 416, 89-96. http://dx.doi.org/10.1016/j.scitotenv.2011.11.071

[10] Rosenlund, M., Berglind, N., Pershagen, G., Jarup, L. and Bluhm, G. (2001) Increased prevalence of hypertension in a population exposed to aircraft noise. Occupational and Environmental Medicine, 58, 769-773. http://dx.doi.org/10.1136/oem.58.12.769

[11] van Kempen, E. and Babisch, W. (2012) The quantitative relationship between road traffic noise and hypertension: A meta-analysis. Journal of Hypertension, 30, 10751086. http://dx.doi.org/10.1097/HJH.0b013e328352ac54

[12] Stokholm, Z.A., Bonde, J.P., Christensen, K.L., Hansen, A.M. and Kolstad, H.A. (2013) Occupational noise exposure and the risk of hypertension. Epidemiology, 24, 135-142.

http://dx.doi.org/10.1097/EDE.0b013e31826b7f76

[13] Talbott, E., Helmkamp, J., Matthews, K., Kuller, L., Cottington, E. and Redmond, G. (1985) Occupational noise exposure, noise-induced hearing loss, and the epidemiology of high blood pressure. American Journal of Epidemiology, 121, 501-514.

[14] van Dijk, F.J., Souman, A.M. and de Vries, F.F. (1987) Non-auditory effects of noise in industry. VI. A final field study in industry. International Archives of Occupational and Environmental Health, 59, 133-145. http://dx.doi.org/10.1007/BF00378491

[15] van Kempen, E., van Kamp, I., Fischer, P., Davies, H., Houthuijs, D., Stellato, R., et al. (2006) Noise exposure and children's blood pressure and heart rate: The RANCH project. Occupational and Environmental Medicine, 63, 632-639.

http://dx.doi.org/10.1136/oem.2006.026831

[16] Bailey, R.H. and Bauer, J.H. (1993) A review of common errors in the indirect measurement of blood pressure. Sphygmomanometry. Archives of Internal Medicine, 153, 2741-2748. http://dx.doi.org/10.1001/archinte.1993.00410240045005

[17] Andren, L., Hansson, L. and Bjorkman, M. (1981) Haemodynamic effects of noise exposure before and after beta 1-selective and non-selective beta-adrenoceptor blockade in patients with essential hypertension. Clinical Science (London), 61, 89s-91s.

[18] Attarchi, M., Golabadi, M., Labbafinejad, Y. and Mohammadi, S. (2012) Combined effects of exposure to occupational noise and mixed organic solvents on blood pressure in car manufacturing company workers. American Journal of Industrial Medicine, 56, 243-251.

[19] Kelishadi, R., Poursafa, P. and Keramatian, K. (2011) Overweight, air and noise pollution: Universal risk factors for pediatric pre-hypertension. Journal of Research in Medical Sciences, 16, 1234-1250.

[20] La Torre, G., Coniglione, D., Scagliusi, A., Ciocci, G., La 
Torre, F., Boccia, A., et al. (2011) Exposure to noise in the general population and hypertension: Results from a pilot case-control study in Rome. Annali di Igiene, 23, 209-217.

[21] Singh, L.P., Bhardwaj, A., Deepak, K.K. and Bedi, R. (2009) Occupational noise exposure in small scale hand tools manufacturing (forging) industry (SSI) in Northern India. Industrial Health, 47, 423-430. http://dx.doi.org/10.2486/indhealth.47.423

[22] Stokholm, Z.A., Bonde, J.P., Christensen, K.L., Hansen, Å.M. and Kolstad, H.A. (2013) Occupational noise exposure and the risk of hypertension. Epidemiology, 24, 135-142.

http://dx.doi.org/10.1097/EDE.0b013e31826b7f76

[23] Weinmann, T., Ehrenstein, V., von Kries, R., Nowak, D. and Radon, K. (2012) Subjective and objective personal noise exposure and hypertension: An epidemiologic approach. International Archives of Occupational and Environmental Health, 85, 363-371. http://dx.doi.org/10.1007/s00420-011-0679-7

[24] Chang, T.Y., Liu, C.S., Bao, B.Y., Li, S.F., Chen, T.I. and Lin, Y.J. (2011) Characterization of road traffic noise exposure and prevalence of hypertension in central Taiwan. Science of the Total Environment, 409, 1053-1057. http://dx.doi.org/10.1016/j.scitotenv.2010.11.039

[25] Hwang, B.F., Chang, T.Y., Cheng, K.Y. and Liu, C.S. (2012) Gene-environment interaction between angiotensinogen and chronic exposure to occupational noise contribute to hypertension. Occupational and Environmental Medicine, 69, 236-242. http://dx.doi.org/10.1136/oemed-2011-100060

[26] Koskinen, H.L., Kauppinen, T. and Tenkanen, L. (2011)
Dual role of physical workload and occupational noise in the association of the metabolic syndrome with risk of coronary heart disease: Findings from the Helsinki Heart Study. Occupational and Environmental Medicine, 68, 666-673. http://dx.doi.org/10.1136/oem.2010.057075

[27] Sbihi, H., Davies, H.W. and Demers, P.A. (2008) Hypertension in noise-exposed sawmill workers: A cohort study. Occupational and Environmental Medicine, 65, 643-646. http://dx.doi.org/10.1136/oem.2007.035709

[28] Lusk, S.L., Gillespie, B., Hagerty, B.M. and Ziemba, R.A. (2004) Acute effects of noise on blood pressure and heart rate. Archives of Environmental Health, 59, 392-399. http://dx.doi.org/10.3200/AEOH.59.8.392-399

[29] Babisch, W. (2008) Road traffic noise and cardiovascular risk. Noise and Health, 10, 27-33. http://dx.doi.org/10.4103/1463-1741.39005

[30] Inoue, M., Laskar, M.S. and Harada, N. (2005) Crosssectional study on occupational noise and hypertension in the workplace. Archives of Environmental Health, 60, 106-110. http://dx.doi.org/10.3200/AEOH.60.2.106-110

[31] Sorensen, M., Hvidberg, M., Hoffmann, B., Andersen, Z. J., Nordsborg, R.B., Lillelund, K.G., et al. (2011) Exposure to road traffic and railway noise and associations with blood pressure and self-reported hypertension: A cohort study. Environmental Health, 10, 92. http://dx.doi.org/10.1186/1476-069X-10-92

[32] Ahranjani Sh, A., Kashani, H., Forouzanfar, M., Meybodi, H. A., Larijani, B., Aalaa, M., et al. (2012) Waist circumference, weight, and body mass index of iranians based on national non-communicable disease risk factors surveillance. Iranian Journal of Public Health, 41, 35-45. 